\title{
The effect of Kodály-based music experiences on joint attention in children with autism spectrum disorders
}

\author{
Natee Chiengchana, Somchai Trakarnrung \\ College of Music, Mahidol University, Nakhon Pathom 73170, Thailand
}

\begin{abstract}
Background: Kodály approach is one of widely used methods in music education and music therapy. The method is based on singing activities that could facilitate young children's social development. Thus, the application of Kodály approach may be appropriate to enhance the joint attention behaviors of children with autism.

Objective: We examined the joint attention of individuals with autism spectrum disorders (ASD) during Kodály-based music experiences.

Methods: The A-B-C-B single-case design was employed to investigate the effectiveness of Kodály-based music experiences on joint attention behaviors of three children, ranging from 7.8 to 11.5 years of age, with autism who had manifested joint attention problems. The experimental sessions consisted of baseline condition (A), group intervention (B), and individual invention session (C). The SCERTS assessment process (SAP) was used to measure joint attention behaviors. The findings were presented using visual inspection.

Results: During baseline sessions, the three participants rarely engaged in joint attention with others. Their behaviors were stable during the first three sessions, with mean occurrence of 5, 9.3, and 4 . In the course of the music intervention, they positively responded to the intervention. The frequencies of their behaviors continuously increased from the first group intervention sessions until the second group intervention sessions. Finally, the second group intervention sessions showed that most of the data points were above the mean of all previous sessions, with mean occurrence of 43.8, 34.1, and 18.8.

Conclusion: The Kodály approach was found one of useful methods in music education that can apply to music therapy to enhance joint attention behaviors of the children with autism. The children were able to learn how to engage in a group setting through singing activities, folk music, and solfège learning.
\end{abstract}

Keywords: Autism spectrum disorders, joint attention, kodály

Autism spectrum disorders (ASD) are developmental disorders referenced under the term Pervasive Developmental Disorder (PDD) [5]. Autistic symptoms are results of a neurological disorder that brings about impairment in the development of communication skills, and lack of social interaction skills, leisure or play activities and almost nonexistent imaginative activities [3, 5, 19].

Social communication impairments are amongst the major difficulties of children with ASD, including difficulties in communicating, playing with others in everyday activities, and sharing joy and pleasure in social relationships [17]. Social communication domain of the SCERT Model was designed to help increase the child's competence, confidence, and

Correspondence to: Natee Chiengchana, College of Music, Mahidol University, Nakhon Pathom 73170, Thailand. E-mail: Chiengchana@yahoo.com active participation in social activities, in two major areas; joint attention and symbol use. The joint attention refers to the developmental capacity that underlies a child's ability to coordinate and share attention, share emotions, express intentions, and engage in reciprocal social interactions [23].

Music therapy is one of the alternative treatments for the purpose of enhancing joint attention behaviors of children with ASD. Music therapists can use the elements of music (melody, rhythm, pitch, dynamics, form) to enhance attention, sharing emotions, and social interaction [1,9]. There have been studies indicating the effectiveness of music therapy on joint attention behaviors of children with ASD. Kim, Wigram, \& Gold [13] employed the improvisational music therapy to increase joint attention behaviors in autistic children. Reitman [18] used an array of music activities to enhance joint attention behaviors of children with autism. Yoo [24] studied the effectiveness 
of musical attention cues on the frequency and accuracy of joint attention behaviors of children with autism.

Nowadays, adaptions of music education approaches to music therapy are widely used in music intervention. Kodály approach is one of widely used methods of music education and music therapy. Kodály himself believed that singing is the most direct method for music learning [11] since languages, speeches, chants, and songs are inextricably intertwined in singing activities. Children can learn social skills through singing games and expand their vocabulary as well as understand words through new songs [6]. Lau [15] found that the singing games in music lessons cultivated young children's social development. According to Kodály approach based on singing activities, it was a reasonable good way to apply this method to encourage the joint attention behaviors of children with ASD through singing activities, including folk music and solfège learning.

As previous literature stated, there was no research conducted on the application of Kodály approach in music therapy so as to enhance joint attention behaviors of people with ASD. Most researches employed Kodály method to encourage spatial reasoning skills of children [10, 12]. For this reason, this study established Kodály-based music experiences to enhance joint attention behaviors of individuals with ASD. The results are beneficial for music therapists and music educators to bring out and apply this intervention to teach children with ASD.

\section{Methods}

This study was approved by the Ethics Committee, Mahidol University. The A-B-C-B single-case design was employed to investigate the effects of Kodálybased music experiences on joint attention behaviors of children with autism spectrum disorders (ASD). The baseline condition (A) was used to observe children's abilities and joint attention behaviors. The intervention (B and C) was Kodály-based music experiences designed to enhance joint attention behaviors of children with ASD, comprising of group intervention (B) and individual intervention (C).

Participants were three children with a primary diagnosis of autism spectrum disorders (ASD) who were patients at Physical Therapy Center, Mahidol University. Selection was based on physician's referrals of children with ASD in accordance with the Diagnostic and Statistical Manual of Mental
Disorders [2]. The written informed consent was obtained from all subjects' parents.

Participant 1: The participant 1 was a male diagnosed with autism spectrum disorder at age 2. At the time of the study, he was 7.8 year old and he had major impairments in expressive communication and social interaction skills. He had never attended music therapy session to remedy his difficulties before but he attended Thai classical music lesson at school. He was able to play Kong wong yai, Thai melodic percussion instrument. He had been attending speech therapy sessions and sensory integration therapy sessions for several years.

Participant 2: The participant 2 was a 9-yearold male who was diagnosed with autism spectrum disorder at age 2.9. At the time of the study he had major difficulties in expressive communication skills, social interaction skills, and behavior. He had never attended music therapy session to heal his impairments before but he had a few experiences in Thai music learning (Ranat ek, Thai melodic percussion instrument) at school. For other therapy, he had been attending speech therapy sessions, sensory integration therapy sessions, and floor time sessions for many years.

Participant 3: The participant 3 was an 11.5year-old male diagnosed with autism spectrum disorder. At the time of the study he had major impairment in receptive and expressive communication, and social interaction skills. He had never attended music therapy session and music learning class before. For other therapy, he had been attending speech therapy session, and sensory integration therapy session.

All participants were assigned to three baseline sessions. After the baseline sessions finished, they were provided to attend music intervention sessions, consisting of first group sessions, individual sessions, and second group sessions as the details shown in table 1. All sessions lasted 30 minutes in length. The SCERTS Assessment Process-Observation (SAP-O) [17] was used to measure joint attention behaviors of each child from baseline sessions to the last treatment sessions.

The SCERTS Assessment Process-Observation (SAP-O) is the observation assessment for children with ASD designed through research by the team of Barry Prizant, Amy Wetherby, Emily Rubin, and Amy Laurent, who have training in Speech-Language Pathology, Special Education, Behavioral and Developmental Psychology, Occupational Therapy and Family-Centered Practice [17]. 
In terms of music therapy, there were two studies that conducted about applying the SAP-O in music therapy clinical practice. These findings revealed the SCERTS goal in music therapy and how music therapists use The SAP-O for children with ASD [21, 22]. Because the SAP-O was a standard assessment tool based on research by professional teams, the SAP-O was employed to assess joint attention behaviors of each child with ASD in this study.

The SCERTS Assessment Process-Observation (SAP-O) consist of three major developmental domains; social communication, emotional regulation, and transactional support. For this study, the researcher employed only social communication domain that was divided into the developmental domains of joint attention and symbol use. Only joint attention domain was used in this study.

The SCERTS Assessment Process-Observation (SAP-O) [17] of joint attention was 3-level rating scales $(0,1$, or 2 points) used to measure joint attention behaviors of each child from baseline sessions to the last treatment sessions. The main observer was the reseacher who observed from video recordings of all sessions. The SAP-O of Joint attention used in this study consisted of eight major items including; (1) engages in reciprocal interaction, (2) shares attention, (3) shares emotion, (4) shares intentions to regulate behavior of others, (5) shares intentions for social interaction, (6) shares intentions for joint attention, (7) persists and repairs communication breakdowns, and (8) shares experiences in reciprocal interaction [17].

In terms of reliability of the SAP-O, the researcher asked an independent observer to view approximately $20 \%$ of the videos to observe and recorded the joint attention behaviors of each participant to establish inter-observer reliability. The videos recorded of each session for each participant were randomly selected to observe the behaviors. Pearson Product Moment Correlation Coefficient was used to test consistency between scores of two observes, researcher and an independent observer. Inter-rater reliability produced a strong and statistically significant correlation $(r=.93, P<0.001)$ that showed high agreement rates between two observers.

\section{Baseline}

During three baseline sessions, participants' joint attention behaviors occurred in the course of class activities were observed at a music therapy room, College of Music, Mahidol University. Observed activities included greeting activities, games, storytelling, or playing with toys etc. No music therapy intervention occurred at any point during baseline condition. Joint attention data were collected for 30 minutes.

\section{Intervention}

Kodály-based music experiences were developed to enhance joint attention behaviors of individuals with ASD. The treatment was based on three key elements of the Kodály method that consists of: (1) the emphasis on singing; (2) the use of folk music; and (3) the use of Solfège learning [11, 16, 20]. The intervention process consisted of three sections as shown below.

1. Greeting section consisted of singing the words "Sawasdee" (Hello.) and "Sabaidee" (I’m good.) in a melodic pattern (sol-mi, sol-la-mi, and do-re-mi) as a call-and-answer song and singing Sawasdee song and Sawasdee Do-Re-Mi song with movement.

2. Music activities section consisted of: (1) individual/group singing with lyrics, solfège, hand signs, and a music scale depicted as a staircase; (2) individual/group singing with a playing instrument; (3) individual/group singing with movement; and (4) reading rhythmic and melodic syllables.

3. Closing section consisted of singing "Thank you teacher song" and singing the words "Bye-bye" in melodic pattern (sol-mi) as a call-and-answer song.

For the study, all sessions took place at the music therapy room, College of Music, Mahidol University. The room was a clean, bright, and quiet private room with good environment and temperature. The equipments in the room consisted of a piano, a sofa, chairs, and a whiteboard. During the study, participants sat on the floor and on chairs across the researcher.

Table 1. The number of sessions

\begin{tabular}{ccccc}
\hline Participants & Baseline (A) & Intervention (B) & Intervention(C) & Intervention (B) \\
\hline 1 & 3 & 5 & 10 & 6 \\
2 & 3 & 5 & 9 & 6 \\
3 & 3 & 5 & 7 & 5 \\
\hline
\end{tabular}




\section{Data analysis}

Visual inspection enabled the researcher to conduct a within-subject analysis of change in level and trend in graphed data [4]. Observed data of joint attention behaviors from baseline to treatment sessions were plotted into line graphs in order to present changes in level and trend of each participant.

\section{Results}

During baseline and treatment sessions, the SAPObservation Form (SAP-O Form) was used to collect participants' responses in joint attention behaviors aspect of social communication. The visual analysis was employed to analyze the data of all sessions and the results were shown as a line graph from the first baseline session to the last treatment sessions. Details are shown below.

\section{Participants 1}

Throughout baseline sessions, he rarely engaged in joint attention with others. His joint attention behaviors were stable in the first three sessions, with a mean occurrence of 5 and a range of 5 to 5 . In the first group intervention sessions, the number of his joint attention behaviors rapidly increased in all sessions, with a mean occurrence of 17.4 and a range of 11 to 28 , except in the $5^{\text {th }}$ session that the behaviors slightly dropped. He showed more joint attention behaviors during the individual intervention sessions. The occurrence of the behaviors gradually increased from the $9^{\text {th }}$ session to the $18^{\text {th }}$ session, especially in the $18^{\text {th }}$ session that the behaviors reached to the highest level. The mean occurrence of joint attention behaviors across individual sessions was 37.4, with a range of 32 to 45 . Finally, the second group intervention sessions showed that most of the data points were above the mean of all previous sessions, with a mean occurrence of 43.8 and a range of 43 to 44 . The occurrence of his joint attention behaviors remained steady until the end of session as shown in Figure 1.

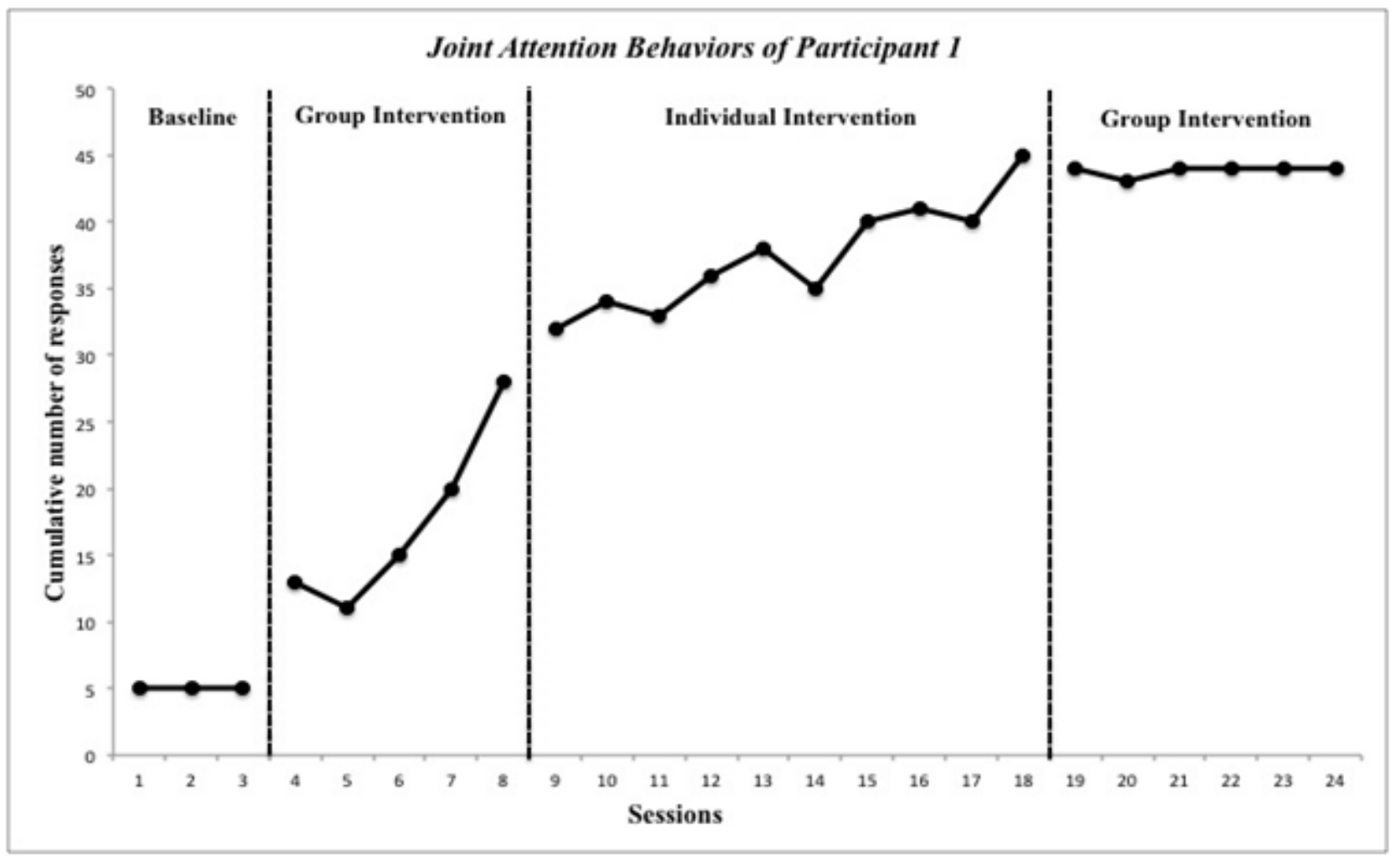

Figure 1. Cumulative numbers of joint attention responses performed by participant 1 during baseline, group intervention, and individual intervention sessions 


\section{Participants 2}

His joint attention behaviors were constant during baseline sessions with a mean occurrence of 9.3 and a range of 9 to 10 . The mean showed that he rarely engaged in joint attention with others. During the first group intervention sessions, the mean occurrence of behavior across the sessions was 14.6, with a range of 11 to 17 . His joint attention behaviors increased about half of the initial number after introducing music intervention in the first session and sharply increased in the $6^{\text {th }}$ session. After that, the behaviors slightly increased and remained constant until the $8^{\text {th }}$ session. During the individual intervention sessions, most of the data points were above the mean of all previous sessions, with a mean occurrence of 28.6 and a range of 23 to 33. All through these sessions, the occurrence of his joint attention behaviors gradually increased in all sessions, especially in the $12^{\text {th }}$ session that the behaviors reached to the highest level of this period. After returning to group sessions, his behaviors highly improved in all sessions apart from the $17^{\text {th }}$ in which his joint attention behaviors slightly dropped, with a mean occurrence of 34.1 and a range of 20 to 41 . The data point of the $17^{\text {th }}$ session was the only one below the mean of the individual intervention period (Figure 2).

\section{Participants 3}

During baseline sessions, he rarely initiated joint attention with others. All data points were stable, with a mean occurrence of 4 and a range of 4 to 4 . After introducing intervention into his group sessions, most of the data points slightly altered above the mean of baseline sessions, with a mean occurrence of 6.8 and a range of 5 to 8 . In the course of the group intervention sessions, his joint attention behaviors noticeably increased from the $4^{\text {th }}$ session to the $5^{\text {th }}$ session and slightly improved until the last session of this period. During individual sessions, he showed more joint attention behaviors. His joint attention sharply increased until $12^{\text {th }}$ session and gradually improved until the end of this period. The mean occurrence of behavior across the sessions was 14.1, with a range of 9 to 17. Lastly, the second group intervention sessions showed that most of the data points were slightly above the mean of all previous sessions, with a mean occurrence of 18.8 and a range of 18 to 19 . His joint attention behaviors slightly improved and were constant until the end of this period as shown in Figure 3.

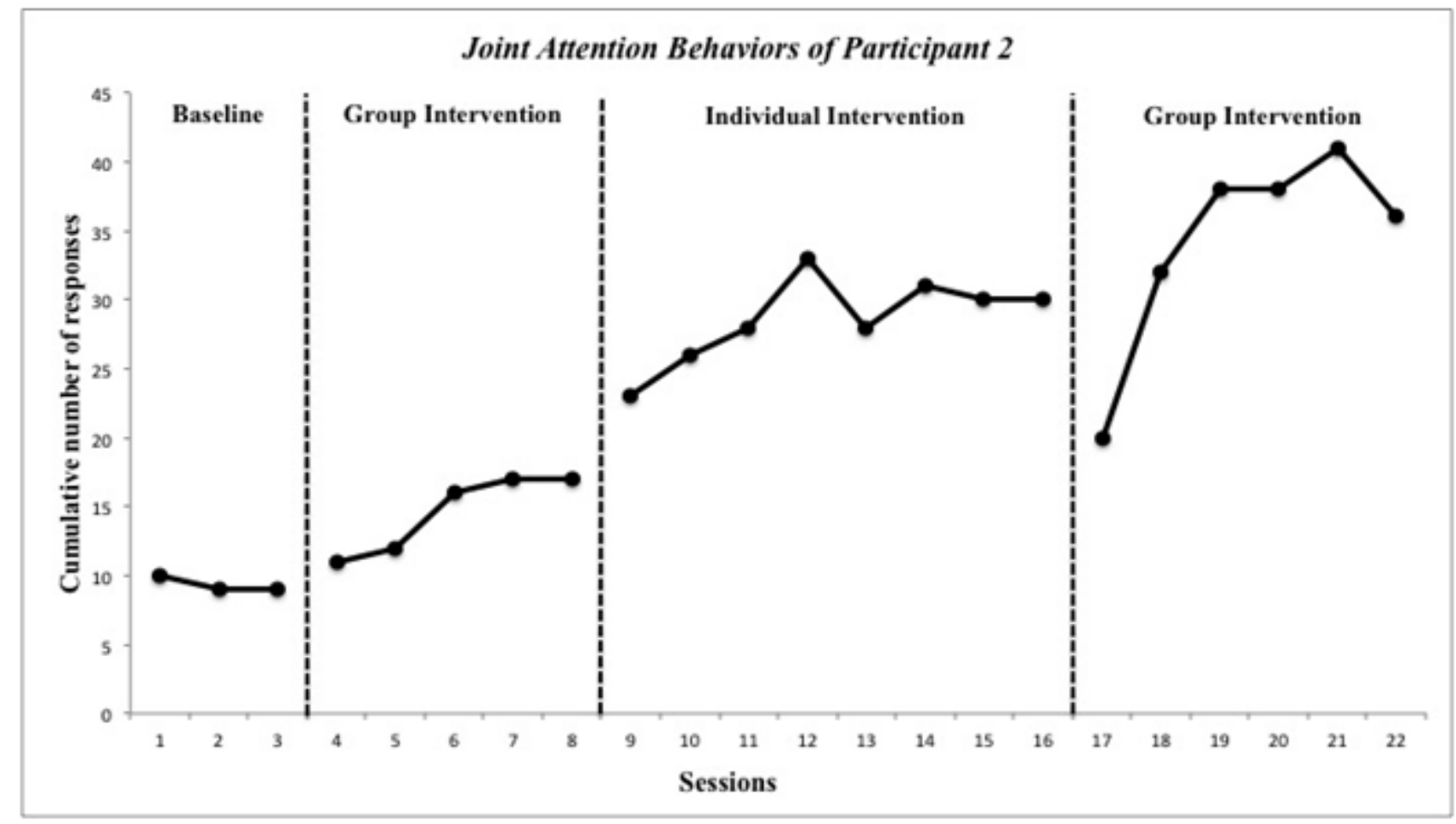

Figure 2. Cumulative numbers of joint attention responses performed by participant 2 during baseline, group intervention, and individual intervention sessions 


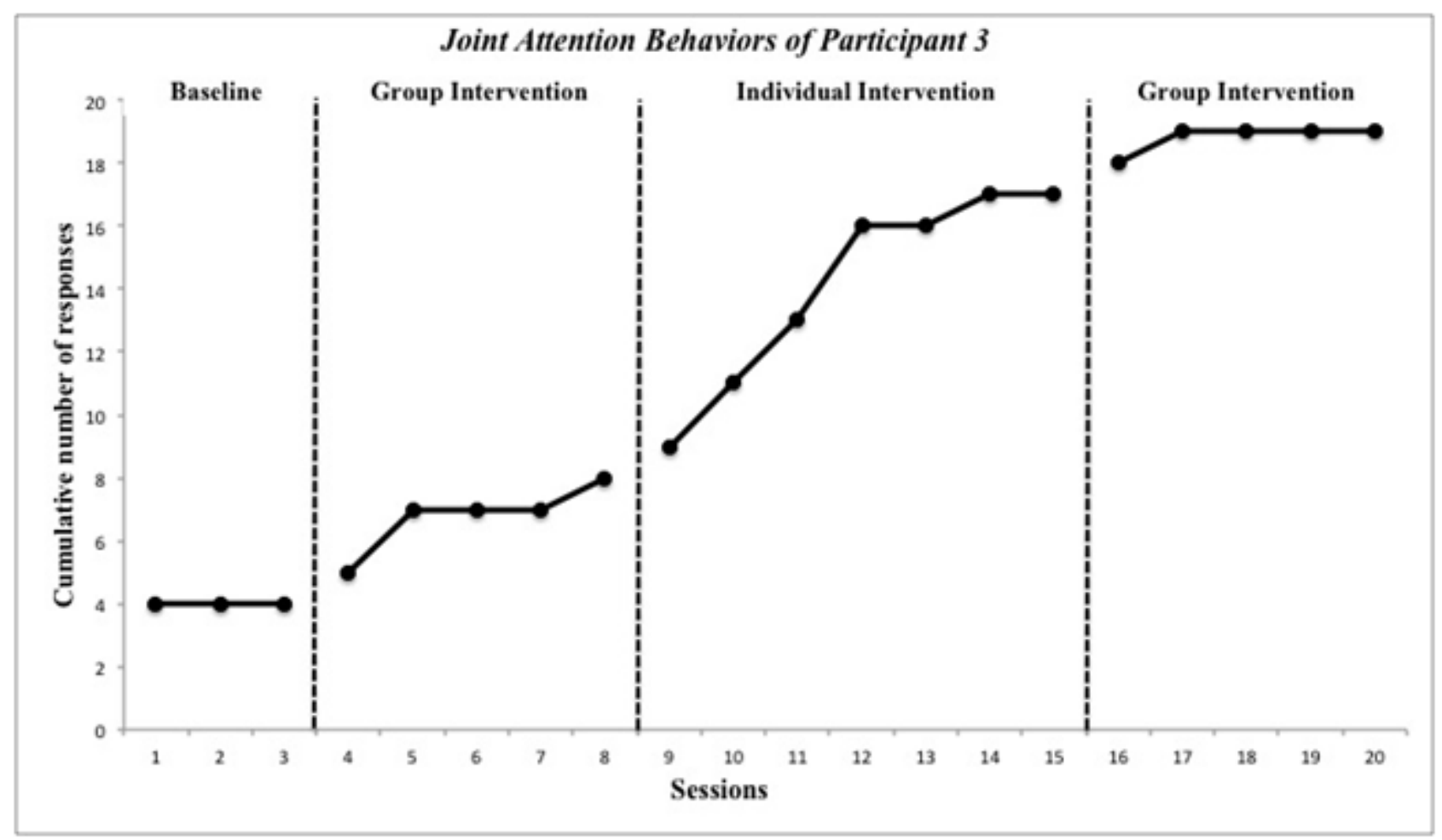

Figure 3. Cumulative numbers of joint attention responses performed by the participant 3 during baseline, group intervention, and individual intervention sessions

\section{Discussion}

This study evaluated the effects of Kodály-based music experiences on joint attention of three children with autism spectrum disorders. The results showed that all participants rarely initiated joint attention with others during baseline sessions. The mean occurrence of behaviors was below the mean of the intervention sessions. While participating, they always avoided eye contact, demonstrated poor attention and did not initiate interaction with others. Although they rarely followed the instruction, most of them understood the instruction, except for the participant 3 who did not know how to participate in the social activities. During Kodálybased music intervention sessions, the results of both group and individual sessions revealed that participants positively responded to the music intervention. The mean occurrence of behavior was above the mean of the baseline sessions. As shown in Figures 1-3, the joint attention behaviors of all participants continuously increased from the first group sessions until the second group sessions. The highest mean occurrence of behaviors was from the second group sessions, followed by the individual sessions, and the first group sessions. Participants were likely to respond to music intervention in the individual sessions more than they did in the first group sessions because they had to learn a lot of new things in a group setting and familiarized with instructions, materials, and other participants in the first group sessions. It was very difficult for them to follow all of instructions and to cooperate in the group activities with other participants in a limited time given. During the individual sessions, because the Kodály-based music intervention was appropriately adapted to the needs of each participant, they showed more responses to instructions and became more familiar with instructions and materials. This suggests that they showed more joint attention behaviors through many activities. After they acclimatized themselves to all instructions, they had more confidence to demonstrate abilities in singing, playing instruments, reading music, and moving to music. They also attentively engaged in the lesson more than before. Thus, during the second group sessions, all participants showed more confidence and abilities to share and engage in making music together with other people in the lesson, with the highest mean occurrence of joint attention behaviors.

Based on the effectiveness of key elements of the Kodály method consisting of the use of singing, folk music, and solfège learning, participants responded 
to the intervention in various ways. In terms of singing activities, Lau [15] revealed the fundamental goal of the singing activities in music lesson was to encourage young children's social development and enhance their social skills. For this study, the researcher discovered illuminating findings that the singing activities could enhance the joint attention skills of three participants. They learned how to greet people through call-andanswer singing activity and learned how to either verbally or nonverbally greet back to the researcher and others. Regarding group singing activity with movement, The Sawasdee (do re mi) song was one of the best activities that could encourage reciprocal interaction through hand clapping movement between the participant and partners. During this activity of the second group intervention sessions, they were able to engage in the activity in the long period of time and they also showed more eye contact when they were clapping the hand together with others. According to the observation, the children concentrated more so as to coordinate between singing and movement when they did the hand clapping together. They also initiated interaction by preparing their hands to the hand clapping position. The results of this study illustrates that the children demonstrate more abilities when they engage in group-singing activities with playing instruments, including melodic and percussion instruments. Additionally, they can also learn how to play the instruments and take turns together with others and to participate or play instruments in a music ensemble.

On folk music learning, Kodály maintained that folk songs are all children's musical mother tongue of in all nations and must be acquired at the very early stage of childhood in the same manner as they learn to speak [11, 20]. Kodály noted that folk songs should be sung in their original language because, by doing so, they increase children's knowledge of languages, and their understanding of the people concerned [20]. Most of the songs used in this study were new compositions based on Thai folk songs and Thai traditional music materials. Because most of melodic and rhythmic patterns of Thai folk songs are complex and difficult for children to sing and learn the rhythm, new simple compositions were created using two or three notes with simple rhythmic patterns. This idea was related to the Kodály's philosophy because he believed that the songs should be appropriate and relevant for specific age groups [11]. Kodály and Bartok collected folk song materials and incorporated the style in their compositions using simple two-note melodies to teach children [14]. In current study, it is observed that the new compositions could help participants to learn with ease. This is because the songs were composed based on Thai language with simple melodies that were easy to sing and memorize the words and rhythms that had simple patterns. On how to practice new songs, Lathom [14] noted that when each song was repeated often enough, every child should feel confident of jointing the activity. In this study, after the participants practiced songs repeatedly, they showed more confidence to perform these songs together with other people and showed more cooperation in the reciprocal interaction. Hence, their joint attention behaviors gradually increased while participating in the activities that related to Lathom's notion detailed above.

With regard to solfège learning, the solfège is the best tool to develop the inner ear and building all musical skills such as sight singing, dictation, ear training, and tonal memory [16]. Hand signs, rhythmic and solfège syllables, and the moveable do system have been used as tools to improve musical literacy of solfège learning $[8,16]$. The hand signs have been used as visual aid to present visualization in space of the high-low relationship among the notes being sung [7]. Likewise, the rhythmic syllables have been used as visual aid to present duration of the rhythm for rhythmic reading, the solfège syllables to present the notes (do re mi fa sol la si do) [7, 8], and the moveable do to support solfège singing in every key. Accodring to the observation during this study, participants positively responded to the solfège learning. They demonstrated better attention and more frequent interaction and eye contact during the solfège activities, especially in music reading activities with rhythmic and solfège syllables. They learned best when they did it through visual aids. Lathom [14] revealed that many of the visual aids used in the Kodály methods could hold the attention of children with short attention spans. This concept is concerned with learning characteristics of the children with autism because most of these children are more successful in visual learning than in verbal learning [1]. The visual aids can be used for the purposeo of giving directions, offering choices, teaching new skills, and providing a structure for an activity [1].

Due to limitations of selecting the participants, the participants used in this study were different in age, language ability, and behavior. The findings 
varied depending on each child. Future research could conduct the children with ASD who were the same age, language ability, and behavior. It will facilitate the researcher to manipulate the music intervention in the group session.

Because this study employed in-depth investigations of a single-case study, the number of participants was quite small and the results of each child were unique depending on age, ability, and behavior. Although the results of three participants were adequate for conclusion in single-case study, the results could not generalize to whole population. The further research could study more participants and selected the participants who represented the target population as an experimental research design. The results of sample will be generalized to the target population.

For this study, there was a limitation of datacollection time. The findings of each child may positively change, if the data-collection time was extended. The further research could plan the datacollection time in one year or more than one year as a longitudinal study. The further research also could examine only one subject in longitudinal study to gain more knowledge and understanding in the effects of Kodály-based music intervention.

Kodály method is internationally well-known method and widely used in the field of music education. In Thailand, the Kodály method was widely employed in teaching music for typical children in school and there were many research studies conducted about teaching music based on Kodály method. However, in terms of music therapy, there were a few research studies that used the Kodály method to enhance non-musical skills of children [10, 12], particularly research in Thailand. The further research could study more about application of the Kodály method in the field of music therapy to enhance non-musical skills of special needs children. The results will be benefit for music therapists to apply this method in clinical practice.

\section{Conclusion}

The Kodály approach is one of useful methods in music education that can apply to music therapy to enhance joint attention behaviors of the children with autism spectrum disorders. These children could learn how to engage in a group setting through music activities, including singing activities, folk music, and solfège learning. The singing activities covered individual/group singing, singing with movement, and singing with playing instruments. All of these treatments motivated the children to learn about social activities such as greeting, sharing attention/intention, and participating in a group setting. The use of folk music and new compositions based on materials of folk music enabled participants to sing, memorize the song, and learn the rhythmic patterns with ease. Concerning the solfège learning, hand signs, rhythmic/ solfège syllables, and moveable do were used as visual aid to improve attention, and increase the frequencies of interaction and eye contact.

\section{Acknowledgements}

This study is a part of a doctoral dissertation, College of Music, Mahidol University. We would like to express our sincere gratitude to the dissertation committee members, Assoc. Prof. Dr. Narutt Suttachitt, Assoc. Prof. Dr. Dena Register, Assoc. Prof. Dr. Lindsey Williams, and Assoc. Prof. Nichara Ruangdaraganon for their thoughtful and insightful help with this study. The authors have no conflicts of interest to declare.

\section{References}

1. Adamek M, Darrow AA. Music in special education. Silver Spring MD: American Music Therapy Association; 2010.

2. American Psychiatric Assoiation. Diagnostic and statistical manual of mental disorders. 4th ed. Washington DC; 2000.

3. Autism Society of America. About autism. [online]. 2009. [cited 2010 Nov 9]; Available from: http://www. autism-society.org/site/PageServer?pagename= about_whatis.

4. Bardon LA, Dona DP, Symons FJ. Extending classwide social skills interventions to at-risk minority students: A preliminary application of randomization tests combined with single-subject design methodology. Behav Disorders. 2008; 33:141-52.

5. Berger DS. Music therapy, Sensory integration and the autistic child. London: Jessica Kingsley Publishers; 2002.

6. Campbell PS, Scott-Kassner C. Music in childhood from preschool through the elementary grades. Belmont CA: Schirmer; 2002.

7. Choksy L. The Kodály method I. Upper saddle river NJ: Prentice-Hall; 1999.

8. Choksy L, Abramson RM, Gillespie AE, Woods D, York F. Teaching music in the twenty-first century. 
Upper Saddle River NJ: Prentice-Hall; 2001.

9. Davis WB, Gfeller KE, Thaut MH. An introduction to music therapy: Theory and practice. Silver Spring MD: The American Music Therapy Association; 2008.

10. Hanson M. Effects of sequenced Kodály literacybased music instruction on the spatial reasoning skills of kindergarten students. Research and Issues in Music Education. 2003; 1.

11. Houlahan M, Tacka P. Kodály today: a cognitive approach to elementary music education. New York: Oxford University Press; 2008.

12. Hurwitz I, Wolff PH, Bortnick BD, Kokas K. Nonmusical effects of the Kodaly music curriculum in primary grade children. J Learn Disabil. 2001; 8:167-74.

13. Kim J, Wigram T, Gold C. The effects of improvisational music therapy on joint attention behaviors in autistic children: A randomized controlled study. J Autism Dev Disord, 2008; 38:1758-66.

14. Lathom W. Application of Kodály concepts in music therapy. J Music Ther. 1974; 11:13-20.

15. Lau WCM. Can children's social skills be enhanced through singing games in music lesson?. Paper presented at: Redesigning Pedagogy International Conference: Research, Policy, Practice; 2005; Singapore.

16. Organization of American Kodály Educators. The Kodály concept. [online]. 2010. [cited 2011 Jun 15]; Available from: http://www.oake.org/AboutUs/ KodalyPhilosophy.aspx.

17. Prizant BM, Wetherby AM, Rubin E, Laurent AC,
Rydell PJ. The SCERTS model: A comprehensive educational approach for children with autism spectrum disorders (Vols.1). Baltimore MD: Brookes; 2006.

18. Reitman MR. Effectiveness of music therapy interventions on joint attention in children diagnosed with autism: A pilot study [dissertation]. Miami FL: Carlos Albizu University; 2005.

19. Sobol ES. An attitude and approach for teaching music to special learners. Lanham MD: The National Association for Music Education; 2008.

20. Szõnyi E. Kodály’s principles in practice: An approach to music education through the Kodály method. New York: Boosey \& Hawkes; 1973.

21. Walworth DD. The use of music therapy within the SCERTS Model for children with autism spectrum disorder. J Music Ther. 2007; 44:2-22.

22. Walworth, DD, Register D, Engel JN. Using the SCERTS model assessment tool to identify music therapy goals for clients with autism spectrum disorder. J Music Ther. 2009; 46:204-16.

23. Wetherby AM, Prizant BM, Schuler AL. Understanding the nature of communication and language impairments. In: Wetherby AM, Prizant BM, editors. Autism spectrum disorders: a transactional developmental perspective. Baltimore MD: Paul Brookes; 2000. p. 109-41.

24. Yoo GE. The effect of musical attention cues on the frequency and accuracy of joint attention behaviors of children with autism [thesis]. Lawrence KS: University of Kansas; 2003. 